\title{
Wrist Actigraphic Approach in Primary, Secondary and Tertiary Care Based on the Principles of Predictive, Preventive and Personalised (3P) Medicine
}

\section{Jens Acker}

Clinic for sleep medicine

Olga Golubnitschaja ( $\nabla$ olga.golubnitschaja@ukbonn.de)

Friedrich-Wilhelms-Universität Bonn

Antje Büttner-Teleaga

University of Witten/Herdecke: Universitat Witten/Herdecke

Kneginja Richter

Paracelsus Medical University Nuremberg

\section{Research Article}

Keywords: Actigraphy, Predictive Preventive Personalised Medicine (PPPM / 3PM), Sleep quality tool, Sleep disturbance, Sleep disorder, Chronobiology, Circadian rhythm, Insomnia, Sleep-wake rhythm, Exposition to light, Mental health, Primary Secondary Tertiary Care, Patient Stratification, Targeted Prevention, Tailored treatment, Individualised patient profiling, Mood, Pain, Fatigue, Post-traumatic stress disorder, Motor activity, Behavioural patterns, Military, Sport medicine, Performance enhancement, Personalised medication, Cancer, Depression, Dementia, ICU, Individual outcomes, Traffic safety, Health Policy, Recommendations

Posted Date: June 18th, 2021

DOI: https://doi.org/10.21203/rs.3.rs-617109/v1

License: (9) (7) This work is licensed under a Creative Commons Attribution 4.0 International License. Read Full License

Version of Record: A version of this preprint was published at EPMA Journal on August 6th, 2021. See the published version at https://doi.org/10.1007/s13167-021-00250-5. 


\begin{abstract}
Sleep quality and duration as well as activity-rest-cycles at individual level are crucial for maintaining physical and mental health. Although several approaches do exist to monitor these parameters, optimal approaches are still under consideration and technological development.
\end{abstract}

Wrist actigraphy is a non-invasive electro-physical method validated in the field of chronobiology to record movements and to allow for monitoring human activity-rest-cycles.

Based on the continuous recording of motor activity and light exposure, actigraphy provides valuable information about the quality and quantity of the sleepwake rhythm and about the amount of motor activity at day and night that is highly relevant for disease prediction, targeted prevention and personalisation of medical services. Being generally used in the field of sleep medicine, actigraphy demonstrates a great potential to be successfully implemented in primary, secondary and tertiary care, psychiatry, oncology, and intensive care, military and sports medicines as well as epidemiological monitoring of behavioural habits as well as well-being medical support, amongst others.

\title{
Prediction of disease development and individual outcomes
}

Activity-rest-cycles have been demonstrated to be an important predictor for many diseases including but not restricted to the development of metabolic, psychiatric and malignant pathologies. Moreover, activity-rest-cycles directly impact individual outcomes in corresponding patient cohorts.

\section{Targeted prevention}

Data acquired by actigraphy are instrumental for the evidence-based targeted prevention by analysing individualised patient profiles including light exposure, sleep duration and quality, activity-rest-cycles, intensity and structure of motion pattern.

\section{Personalised Therapy.}

Wrist actigraphic approach is increasingly used in clinical care. Personalised measurements of sedation/agitation rhythms are useful for ICU-patients, for evaluation of motor fatigue in oncologic patients, for an individual enhancement of performance in military and sport medicine. In the framework of personalised therapy intervention, patients can be encouraged to optimise their behavioural habits improving recovery and activity patterns. This opens excellent perspectives for the sleep-inducing medication and stimulants replacement as well as for increasing the role of participatory medicine by visualisation and encouraging favourable behavioural patterns of the individual.

\section{Introduction}

Sleep quality and duration are crucial for maintaining physical and mental health[1,2] as well as for individual outcomes in a spectrum of suboptimal health conditions, external and internal risk factors with health adverse effects[3-6] as well as pathologies under treatment[7-10].

Contextually, individualised sleep quality monitoring is essential to analyse individual sleep patterns, to predict sleep disorders and associated pathologies followed by targeted prevention and treatments tailored to the personalised patient profile [9, 11-14]. This approach is conform with principles of predictive, preventive and personalised medicine (PPPM / 3PM) [15].

In the field of sleep medicine, wrist activity is used for estimating sleep parameters over periods of days to weeks [16]. Devices developed in the branch allow for monitoring over a long period of time in the patient's natural environment. The actigraphy approach has been used for nearly 60 years to study sleep and determine twenty-four-hour motor activity [17]. Corresponding devices can be worn on the wrist, ankle or waist. Usually, actigraphy is completed with sleep logs and most used for measuring sleep latency (SL), total sleep time (TST), wake after sleep onset (WASO) and sleep efficiency (SE; corresponds TST / time in bed TIB).

Investigating sleep quality at home with objective means like actigraphy is supported by growing evidence on the importance of sleep-wake rhythm organization and sleep duration per se [18, 19].

In recent years, actigraphy has been increasingly used in clinical settings. Modern medical actigraphs have achieved increased accuracy and reliability with improved piezoelectric motion sensors, lithium batteries and extended memory capabilities.

With the increasing availability of inexpensive actigraphy in wearables, promising applications are opening in the field of sleep medicine and in predictive, preventive, and personalised medicine. These will be presented and discussed in the following.

\section{Actigraphy In The Field Of Sleep Medicine}

\subsection{Increasing recognition of actigraphy in the field of sleep medicine}

In 1995, the ASDA provided first recommendations for the use of actigraphy in the clinical assessment of sleep disorders [20]. Actigraphy was labelled as a complementary method for documenting multiday rest-activity patterns [21] and later on used both in the field of sleep medicine and sleep research.

The Standards of Practice Committee of the American Academy of Sleep Medicine (AASM) updated the "Practice Parameters for Actigraphy" in 2007 [22] and 2018 [23], leading to increased prominence in the field of clinical sleep medicine. 
To date, the use of actigraphy is recommended in the following sleep disorders or circadian rhythm sleep-wake disorders [24]:

- to estimate sleep parameters in adult patients with insomnia disorder (conditional)

- in the assessment of paediatric patients with insomnia disorder (conditional)

- in the assessment of adult patients with circadian rhythm sleep-wake disorder (conditional).

- in the assessment of paediatric patients with circadian rhythm sleep-wake disorder (conditional)

- integrated with home sleep apnea test devices to estimate total sleep time during recording (in the absence of alternative objective measurements of total sleep time) in adult patients suspected of sleep-disordered breathing (conditional)

- to monitor total sleep time prior to testing with the Multiple Sleep Latency Test in adult and paediatric patients with suspected central disorders of hypersomnolence. (conditional)

- to estimate total sleep time in adult patients with suspected insufficient sleep syndrome (conditional).

The use of actigraphy in place of electromyography for the diagnosis of periodic limb movement disorder in adult and paediatric patients is not recommended anymore.

\subsection{Recommendations by the International Classification of Sleep Disorders ICSD-3}

The new version of the International Classification of Sleep Disorders ICSD-3 [25] recommends the use of actigraphy in numerous diagnostic groups:

- central disorders of hypersomnolence (narcolepsy, hypersomnia)

- behaviourally induced insufficient sleep syndrome (BISS)

- long sleeper (normal variant)

- circadian rhythm sleep-wake disorders

- delayed sleep-wake phase disorder

- irregular sleep-wake rhythm disorder

- non-24-hour sleep-wake rhythm disorder

- shift work disorder and

- circadian sleep-wake disorder not otherwise specified.

\subsection{An issue of reimbursement for the clinical implementation of actigraphy}

There is a discrepancy between the recommendation to implement actigraphy on one hand but still problematic reimbursement on the other hand [26, 27]. It is evidently a bottle-neck in the clinical application of actigraphy that in most countries, the reimbursement of actigraphy is not implemented [28] or regulated inconsistently [29].

\section{Actigraphy Application In The Broader Focus Of Sleep Medicine}

Everyday activity patterns play an important role in the diagnostic and treatment of sleep disorders. When measuring total sleep time under free-living conditions, it is important to evaluate objective measures that are less susceptible to reporting biases than sleep logs.

\subsection{Actigraphy is instrumental to quantify sleep duration}

Actigraphy could provide greater degrees of objectivity of sleep measurements than subjective or parental reports. In contrast with the growing scientific and clinical interest in this method, age-appropriate and gender-based data are still missing [30,31]. Additionally, customizing the standard actigraphy settings may be necessary in certain populations [32]. Recently studies found that objective actigraphy-based sleep data were not well correlated with subjective sleep quality [33].

Other studies with depressed insomniacs showed a superior actigraphy agreement with polysomnography data compared to sleep diaries [34].

\subsubsection{Long-term monitoring of sleep-wake data with traditional actigraphy device}

The potential health risk of sleep deprivation and long-term sleep curtailment has been repeatedly discussed in recent literature [35-38].

Motor activity recording by wrist actigraphy in a famous sleep researcher over period of 33 years shows the great impact society exerts on the structure of the sleep-wake-cycle [39]. The weekly $1 \mathrm{~h}$ sleep prolongation on weekends vanished post-retirement.

The phenomenon of social jetlag is linked to several adverse health outcomes including obesity and cardiometabolic risk [40]. Actigraphy provides objective behavioural measures of sleep patterns that are not influenced by retrospective reporting bias, in contrast to sleep logs for example.

\subsubsection{Insufficient sleep duration and circadian rhythm disruption}


Insufficient sleep per se is the first cause for several adverse health consequences [41]. Impairments in physiological functioning, cognitive deficits and emotional effects ranging from mood instability to depressive symptoms may be caused by insufficient rest times. Diagnostic criteria for behaviourally induced insufficient sleep syndrome (BISS) according to ICSD-3 include an urge to sleep, daytime lapses into sleep for three months and a low sleep duration according to age [25]. Some authors proposed to define sleep insufficiency as a potential non-communicable disease [42].

Several studies establish a link between fragmented sleep, sleep deprivation measured by actigraphy and increased obesity susceptibility. Today, therefore, addressing sleep deprivation in the general population is a major challenge for the future for all industrialised nations [43].

Epidemiological studies indicate strong links between the circadian clock and human health [44]. The disruption of complex interacting metabolic processes, for example through shift work, results in an increased risk of metabolic syndrome, obesity and consequently diabetes [45].

\subsubsection{Discriminating between sleepiness and fatigue}

In the borderland of fatigue, sleepiness, and tiredness, discriminating behaviourally induced sleepiness from disease-related fatigue can be difficult. Behaviourally induced insufficient sleep syndrome (BISS) can be unmasked by combining sleep diaries and actigraphy. Sleepiness can be objectified by using a standardised procedure for measuring sleepiness called Multiple Sleep Latency Test (MSLT) [46].

\subsubsection{Actigraphy as a tool for keeping a control over safety in a spectrum of areas}

Per evidence, sleep disorders are underestimated and underdiagnosed in the primary care [47]. Therefore, actigraphy is suitable to uncover reporting bias [27]. In some studies, actigraphy was used for monitoring adherence to study procedures [48]. Assessment of functional recovery in paediatric patients perioperative care could be an important addition for improving individual care [49]. The correct diagnosis and treatment of daytime sleepiness remains a relevant contribution of sleep medicine to the prevention of the issue related accidents e.g. from the perspective of the traffic safety as well as professional and private safety [50].

\section{Actigraphy Application Opportunities Beyond The Sleep Medicine}

Recently, several groups reported use of actigraphy in different areas of application.

\subsection{Monitoring of sedation/agitation levels in intensive care unit (ICU)}

Accelerometer based devices, placed on the nondominant wrist, were correlated to measures of a proven sedation/agitation scale. The authors found a strong correlation between the sedation/agitation levels and the actigraphy data and concluded that actigraphy may have the potential to be used as a tool for automated objective real-time monitoring of sedation/agitation levels for patients in ICUs [51]. They proposed, that actigraphy data could be presented at bedside, freeing up nursing time for other patient care activities and allow monitoring the patients in absence of the nursing staff. Future research is needed in this area, before decision making in critically ill populations can be supported [52].

\subsection{Monitoring activity to estimate energy expenditure}

The WHO started to include regular physical activity (PA) among the global recommendations related to health and non-communicable disease prevention [53]. In most developed countries, PA levels stay far behind the given recommendations in terms of intensity and duration. Activity behaviour among middleaged German adults for example stays far behind the WHO recommendations in $>85 \%$ of the subjects [54].

Actigraphs could be used for estimation of Energy Expenditure, as they save information about frequency and intensity of PA. Problematic is the missing integration of type of PA [55]. Modern prevention recommendations aim at changing health behaviour and in particular increasing physical activity [56]. In fact, the objective change in behaviour is rarely tracked and objectified. Actigraphy offers the possibility to verify the implementation of expert recommendations. Participants in prevention programmes can receive visualised feedback on the extent to which recommendations are implemented in everyday behaviour.

\subsection{Cancer related fatigue}

Sleep-wake rhythm disturbance in hospital environment is highly relevant for the degree of cancer related fatigue. For example, objective actigraphic data showed a greater inter-daily instability of sleep-wake-rhythm in paediatric patients with acute lymphoblastic leukaemia. Corresponding intervention options aimed to improve sleep-hygiene and individual physical activity are highly desirable to be developed based in the actigraphic approach [57].

\subsection{Dementia and $\mathrm{MCl}$}

The severity of sleep-wake rhythm disorders is related to the severity of neuropsychological dysfunction in patients with mild cognitive impairment (MCI) [58], and it is widely accepted, that sleep problems are common amongst patients suffering from the $\mathrm{MCI}$ [59]. To this end, the prevalence of sleep disturbance may be intermediate between normal ageing and dementia. Thus, alterations in the circadian structure may be early indicators for age-related cognitive decline. In a pilot study, the delay of the acro-phase (time a rhythm peaks) was found in a subgroup of patients that showed cognitive decline, while the general parameters of sleep did not differ significantly. It has been concluded that changes in circadian rhythm may be a precursor of clinically relevant cognitive decline in older adults [60].

\subsection{Military medicine}

In military personnel with post-traumatic stress disorder, an impaired nocturnal melatonin secretion has been demonstrated, compared to controls [61]. For this patient cohort, individualised therapy algorithms can be established and controlled with the help of actigraphy. 


\subsection{Monitoring individual sleep quality under pandemic-related movement restrictions}

During the COVID-19 pandemic, analysis of cloud-based activity data has shown significant changes at the population level in terms of sleep duration and bedtime [62].

Due to the existing baseline restrictions in many countries, physical activities have decreased significantly with average sleep times increasing [63].

To this end, actigraphic measurements might be useful to improve day-night rhythms individually and to provide recommendations under lasting pandemic conditions.

\section{Actigraphy Provides Significant Advantages For The 3pm Approach}

A widespread use of actigraphy could provide sleep disturbances/deficits risk assessment for primary care. Actigraphy enables an objective recording of everyday behaviour patterns that advances a descriptive survey approach [27, 64]. It can fill gaps in the report of nocturnal behaviour and provide substantial information additionally to sleep diaries and interviews [65]

Detailed tracking of patient routines in the home environment can significantly improve an individualised patient profiling approach contributing to the paradigm change from reactive to predictive, preventive and personalised medicine [66].

To this end, the great advantage of the actigraphy is that it can provide valid information about nightly waking hours and sleep patterns, particularly in case of children, dementia patients, patients with communication handicaps and malcompliance [65].

\section{Actigraphy is instrumental for participatory medicine - Increasing level of motivated prevention and acceptance by the patient}

In several prospective studies, actigraphy was used over the 24-hour period to record daily activity versus inactivity phases. Increased mortality for subjects with a prevalence of sedentary patterns was the most important finding of this research [67]. To this end, actigraphy might be the best tool to communicate the data to the patient illustrating corresponding recommendations to motivate them for improved behavioural patterns $[68,69]$.

\subsection{Innovative concepts for extracting information from conventional actigraphy data}

New concepts of the actigraphy data processing allow for extracting information over the $24 \mathrm{~h}$ period of time [70]. The focused observation of inactivity during sleep phases and the calculation of intra-individual activity dynamics over the course of the night enable sleep structure and sleep dynamics characterisation with relatively simple means. Furthermore, in countries with a restricted availability of polysomnography diagnostics, the innovative and highly cost-effective actigraphy approach can be utilised to predict sleep disorders followed by the targeted intervention such as morning light exposure combined with physical activity leading to the significantly improved symptoms of delayed sleep phase syndromes without further medication [71].

\subsection{Actigraphy in psychiatry supports principles of 3P medicine}

Well-being in the population can be significantly improved by reducing sleep disorders [72]. Further, for patients suffering from sleep disorders but without depression history, the risk of developing a depression can be significantly reduced by early detection and timely treatment of insomnia [73]. According to recently published statistics, insomnia is an independent predictor for the development of anxiety disorders, alcohol abuse and psychotic disorders, amongst others $[74,75]$. Contextually, individualised prediction and targeted prevention of sleep disorders would sufficiently contribute to the field of psychiatry that demands further research.

Early detection of sleep-wake-rhythm disturbances and insomnia is supportive for a cost-effective prevention and personalised treatment of the related psychiatric disorders.

Actigraphy can provide insights into actual nocturnal sleep fragmentation during ongoing therapy, as it has been demonstrated for the post-traumatic stress disorder. In a sample of patients with schizophrenia-spectrum disorders, reduced motor activity (measured by wrist actigraphy) was a marker for functional deterioration in the course of the disease. In patients with multiple episodes, motor activity was higher during the first episode [76]. The promotion of physical exercise in this patient group may be supported using objective data, generating a dynamic feedback for patients [77].

Moreover, healthy population may significantly benefit from those preventive measures aiming at the improved sleep quality protecting individuals against related psychiatric and other pathologies [78]

\section{Individualised Actigraphy Application - Case Studies}

\subsection{Primary care: Sub-optimal health conditions prior to clinical manifestation of a disease}

Long periods of bed rest and low levels of physical activity are associated with increased cardiovascular risk [79] and mortality [80]. It is extremely difficult to comprehensively assess the daily habits of patients in a short period of time in a GP's brief contact. In particular, the survey of regular physical activity 
according to the recommendations of the World Health Organisation remains a challenge [53]. The activity behaviour among middle-aged adults remains highly insufficient [54].

The 45-year-old patient was referred by his general practitioner with the core symptoms of therapy-resistant sleep disturbance and non-restorative night sleep. The focus of the problem at the time of referral was the poor quality of sleep, attempts at improvement with sedating substances were unsuccessful.

The 14-day actigraphy initiated after taking the patient's history showed a predominantly sedentary lifestyle with almost complete avoidance of physical activity. Significant deconditioning was present, and physiotherapy was indicated.

The patient underwent a cycle of outpatient medical training therapy and reported an improvement in his daily well-being as well as a decrease in the sleep problem that initially led to his presentation.

The use of actigraphy in this case enabled the support of sustainable behaviour change. The patient's original focus on a health disorder ("sleeping sickness") could be expanded to a broader understanding of the concept of health ("I can be more active in my everyday life and live healthier").

\subsection{Secondary care (to avoid complications and cascading pathologies)}

A careful family history opens additional perspectives in the context of therapy, as does the use of objective diagnostics, which can be of importance for therapy [81].

A 65-year-old pensioner was referred by his family doctor because of his sleep disturbances attributed to a decrease of the benzodiazepine effect of the hypnotic therapy prescribed for many years.

After a prolonged actigraphy was performed over 4 weeks, an unusual pattern of sleep fragmentation was revealed. An extended family history was taken to adjust the intended behavioural therapy for insomnia (CBT-I).

Considerable computer gaming activity and imminent indebtedness became evident. Specialist psychiatric treatment for the underlying disorder "gambling addiction" was initiated. A rapid change in the patient's behaviour has been achieved through 24 -hour support by family members. Medium-term psychiatric therapy was not desired by the patient.

The relationship between insomnia symptoms and obsessive-compulsive symptoms was also postulated in the context of the corona pandemic [82]. In the presented patient case, however, no increased psychological stress was subjectively reported due to the corona crisis.

If we transfer the patient case to the age group of adolescents, there are connections between media consumption, playing video games and the development of sleep disorders $[83,84]$. Prolonged media consumption can cause or complicate the course of psychiatric illnesses through sleep time reduction and social isolation [85].

\subsection{Tertiary care}

57-year-old patient with chronic pain syndrome on escalated opiate therapy was referred because of significant daytime fatigue combined with pain and sleep disturbances.

Actigraphy shows a predominantly abolished circadian rhythm with rest phases distributed throughout the day. Painkillers and sedative substances are taken in medium to high doses only when needed. General practitioner prescription schemes are no longer observed. The patient was hospitalised for reduction of pain medication and readjustment of medication.

In our case, the use of the actigraphy method in cooperation with the pain physician led to a changed view of the subjective patient information regarding pain experience and prevented the further escalation of pain therapy.

From a sleep- and chronomedical point of view, light therapy in the morning (breakfast on the balcony) was recommended, as well as retarded melatonin added to the basic therapy in the evening [86].

Finally, the establishment of an outpatient service led to a pain therapy based on medical and pharmacological criteria [87]. With a reduced total medication, an improved patient condition has been achieved.

\subsection{Help in adolescence: A psychiatric patient with suspended day-night structure}

Adolescents frequently complain of academic and personal difficulties in psychiatric outpatient clinics, which often leads to a standard psychiatric diagnosis. Especially in the presence of relevant sleepiness and fatigue, the use of actigraphy can provide complementary and high relevant information towards circadian rhythm disorders $[88,89]$.

Taking into account the principles of chronomedical therapy and the two-process model of sleep [90], an improvement of the day-night rhythm can be achieved through regular eating times, improvement of the activity level with simultaneous light exposure and melatonin administration [91].

After normalisation of the day-night rhythm, the patient has been admitted to long-term psychiatric therapy.

\section{Conclusions, Expert Recommendations In The Framework Of 3pm}


Wrist Actigraphy is an important tool for measuring human activity-rest-cycles and recording movements conform with principles of Predictive, Preventive and Personalised Medicine, utilising the international classification of sleep disorders (ICSD-3) and following recommendations of AASM.

The paradigm change from reactive to Predictive, Preventive and Personalised Medicine (PPPM) is in the focus of the actigraphy applicable to

- establishing new strategies for increased predictive, preventive, and personalised capacity as well as enhanced cost-efficiency of healthcare systems,

- stratifying patients and

- improving individual outcomes at the level of primary, secondary and tertiary care.

Improving physical activity and behaviour patterns have a potential to increase both - the life quality and expectance of healthy as well as physically and/or mentally ill sub-groups in the population [92].

Further, in context of participatory medicine, both healthy individuals and patients express their interest in monitoring and to improve their own health wearing different life-style wearables. To satisfy these needs, much equipment is available today, which, however, is not valid for this purpose and can even produce harm to their users. In contrast, wrist actigraphy is a cost-effective validated tool highly recommended and implementable for an individualised predictive approach followed by the targeted prevention of a broad spectrum of sleep-related, physical and mental disorders. The approach is also complementary to the personalised treatment of clinically manifested diseases to avoid downstream cascading pathologies and, therefore, improving individual outcomes.

\section{Abbreviations}

AASM: American Academy of Sleep Medicine

ASDA: American Sleep Disorders Association

CBT-I: Cognitive Behavioural Therapy for Insomnia

GP: General Practitioner

ICU - Intensive care unit

ICSD-3: International Classification of Sleep Disorders $3^{\text {rd }}$ Revision

$\mathrm{MCl}$ - Mild Cognitive Impairment

WHO - World Health Organization

3PM / PPPM - Predictive preventive personalised medicine

\section{Declarations}

Authors' contribution: J.A. has concepted and together with K.R. coordinated the study. The manuscript was drafted by J.A., A.B.T. and K.R.

O.G. has contributed with her expertise in $3 \mathrm{P}$ medicine and created the final version of the manuscript.

All authors have read and agreed to the published version of the manuscript.

Funding:

Open Access funding enabled and organised by Project DEAL.

\section{Data availability}

Not applicable.

\section{Code availability}

Not applicable.

\section{Ethical Approval:}

Not applicable for the literature research. For analysing presented cases, the database of the Clinic for Sleep Bad Zurzach, Switzerland has been used with the permission of the responsible ethical unit.

\section{Conflict of interest:}

Authors declare no conflict of interest. 


\section{Statement of informed consent:}

Not applicable.

\section{Statement of human and animal rights:}

Not applicable.

\section{References}

1. Archer SN, Oster H. How sleep and wakefulness influence circadian rhythmicity: effects of insufficient and mistimed sleep on the animal and human transcriptome. J Sleep Res. 2015;24:476-93. doi:10.1111/jsr.12307.

2. Archer SN, Schmidt C, Vandewalle G, Dijk D-J. Phenotyping of PER3 variants reveals widespread effects on circadian preference, sleep regulation, and health. Sleep Med Rev. 2018;40:109-26. doi:10.1016/j.smrv.2017.10.008.

3. Kucera R, Pecen L, Topolcan O, Dahal AR, Costigliola V, Giordano FA, Golubnitschaja O. Prostate cancer management: long-term beliefs, epidemic developments in the early twenty-first century and 3PM dimensional solutions. The EPMA Journal. 2020;11:399-418. doi:10.1007/s13167-020-00214-1.

4. Brain. Effects of sleep and sleep loss on immunity and cytokines. Behavior Immunity. 2002;16:503-12. doi:10.1016/S0889-1591(02)00003-X. IRWIN M.

5. Krueger JM, Clinton JM, Winters BD, Zielinski MR, Taishi P, Jewett KA, Davis CJ. Involvement of cytokines in slow wave sleep. Prog Brain Res. 2011;193:39-47. doi:10.1016/B978-0-444-53839-0.00003-X.

6. Huang Y, Zhao N. Mental health burden for the public affected by the COVID-19 outbreak in China: Who will be the high-risk group? Psychology. Health Medicine. 2021;26:23-34. doi:10.1080/13548506.2020.1754438.

7. Uzunköprü C, Beckmann Y. Flammer syndrome in multiple sclerosis: diagnostics, prediction, and personalization of treatments. The EPMA Journal. 2019;10:437-44. doi:10.1007/s13167-019-00179-w.

8. Mogavero MP, DelRosso L, Fanfulla F, Bruni O, Ferri R. Sleep Disorders and Cancer: State of the Art and Future Perspectives. Sleep Med Rev. 2020;56:101409. doi:10.1016/j.smrv.2020.101409.

9. Richter K, Kellner S, Hillemacher T, Golubnitschaja O. Sleep quality and COVID-19 outcomes - The Evidence-based Lessons in the Framework of Predictive, Preventive and Personalised (3P) Medicine. EPMA Journal. 2021.

10. Oswald KA, Richard A, Hodges E, Heinrich KP. Sleep and neurobehavioral functioning in survivors of pediatric cancer. Sleep Med. 2021;78:153-9. doi:10.1016/j.sleep.2020.12.026.

11. Kitamura T, Miyazaki S, Sulaiman HB, Akaike R, Ito Y, Suzuki H. Insomnia and obstructive sleep apnea as potential triggers of dementia: is personalized prediction and prevention of the pathological cascade applicable? EPMA J. 2020;11:355-65. doi:10.1007/s13167-020-00219-w.

12. Richter K, Baumgärtner L, Niklewski G, Peter L, Köck M, Kellner S, et al. Sleep disorders in migrants and refugees: a systematic review with implications for personalized medical approach. EPMA J. 2020;11:251-60. doi:10.1007/s13167-020-00205-2.

13. Polivka J, Pesta M, Rohan V, Celedova L, Mahajani S, Topolcan O, Golubnitschaja O. Risks associated with the stroke predisposition at young age: facts and hypotheses in light of individualized predictive and preventive approach. The EPMA Journal. 2019;10:81-99. doi:10.1007/s13167-019-00162-5.

14. Mehta R, Giri S, Mallick BN. REM sleep loss-induced elevated noradrenaline could predispose an individual to psychosomatic disorders: a review focused on proposal for prediction, prevention, and personalized treatment. The EPMA Journal. 2020;11:529-49. doi:10.1007/s13167-020-00222-1.

15. Golubnitschaja O, Baban B, Boniolo G, Wang W, Bubnov R, Kapalla M, et al. Medicine in the early twenty-first century: paradigm and anticipation - EPMA position paper 2016. EPMA Journal. 2016;7:23. doi:10.1186/s13167-016-0072-4.

16. Acker JG, Becker-Carus C, Büttner-Teleaga A, Cassel W, Danker-Hopfe H, Dück A, et al. The role of actigraphy in sleep medicine. Somnologie Schlafforschung und Schlafmedizin; 2021.

17. Kupfer DJ, Detre TP, Foster G, Tucker GJ, Delgado J. The application of Delgado's telemetric mobility recorder for human studies. Behav Biol. 1972;7:58590. doi:10.1016/s0091-6773(72)80220-7.

18. Grandner MA, Hale L, Moore M, Patel NP. Mortality associated with short sleep duration: The evidence, the possible mechanisms, and the future. Sleep Med Rev. 2010;14:191-203. doi:10.1016/j.smrv.2009.07.006.

19. Itani O, Jike M, Watanabe N, Kaneita Y. Short sleep duration and health outcomes: a systematic review, meta-analysis, and meta-regression. Sleep Med. 2017;32:246-56. doi:10.1016/j.sleep.2016.08.006.

20. Thorpy M, Chesson A, Derderian S. Practice parameters for the use of actigraphy in the clinical assessment of sleep disorders. American Sleep Disorders Association Sleep. 1995;18:285-7. doi:10.1093/sleep/18.4.285.

21. Sadeh A, Hauri PJ, Kripke DF, Lavie P. The Role of Actigraphy in the Evaluation of Sleep Disorders. Sleep. 1995;18:288-302. doi:10.1093/sleep/18.4.288.

22. Morgenthaler T, Alessi C, Friedman L, Owens J, Kapur V, Boehlecke B, et al. Practice parameters for the use of actigraphy in the assessment of sleep and sleep disorders: an update for 2007. Sleep. 2007;30:519-29.

23. Smith MT, McCrae CS, Cheung J, Martin JL, Harrod CG, Heald JL, Carden KA. Use of Actigraphy for the Evaluation of Sleep Disorders and Circadian Rhythm Sleep-Wake Disorders: An American Academy of Sleep Medicine Systematic Review, Meta-Analysis, and GRADE Assessment. J Clin Sleep Med. 2018;14:1209-30. doi:10.5664/jcsm.7228. 
24. Smith MT, McCrae CS, Cheung J, Martin JL, Harrod CG, Heald JL, Carden KA. Use of Actigraphy for the Evaluation of Sleep Disorders and Circadian Rhythm Sleep-Wake Disorders: An American Academy of Sleep Medicine Clinical Practice Guideline. J Clin Sleep Med. 2018;14:1231-7. doi:10.5664/jcsm.7230.

25. American Academy of Sleep Medicine. International classification of sleep disorders Third Edition: ICSD-3. 3rd ed. Darien, IL; 2014.

26. Auger RR, Varghese R, Silber MH, Slocumb NL. Total sleep time obtained from actigraphy versus sleep logs in an academic sleep center and impact on further sleep testing. Nature Science of Sleep. 2013;5:125-31. doi:10.2147/NSS.S48970.

27. Lewis O, Morkous S, Strohl KP, Rosen CL. Actigraphy as a "Truth-Buster". J Clin Sleep Med. 2015;11:1466-9. doi:10.5664/jcsm.5292.

28. AASM. Sleep Study Billing and Diagnostic Codes \& Guidelines. https://aasm.org/clinical-resources/coding-reimbursement/coding-faq/. Accessed 19 Jan 2020.

29. Philips Respironics. Helpful hints for filing: Actigraphy studies. https://www.google.de/url? $s a=t \& r c t=j \& q=\& e s r c=s \&$ source $=$ web\&cd=2\&ved=2ahUKEwjN6KuxzZDnAhUBaQKHR2wCL4QFjABegQIAxAB\&url=http\%3A\%2F\%2Fincenter.medical.philips.com\%2Fdoclib\%2Fenc\%2F9838742\%2FActigraphyReimbursementHelpfulHin Accessed 19 Jan 2020.

30. Galland BC, Short MA, Terrill P, Rigney G, Haszard JJ, Coussens S, et al. Establishing normal values for pediatric nighttime sleep measured by actigraphy: a systematic review and meta-analysis. Sleep 2018. doi:10.1093/sleep/zsy017.

31. Short MA, Gradisar M, Lack LC, Wright H, Carskadon MA. The discrepancy between actigraphic and sleep diary measures of sleep in adolescents. Sleep Med. 2012;13:378-84. doi:10.1016/j.sleep.2011.11.005.

32. Kapella MC, Vispute S, Zhu B, Herdegen JJ. Actigraphy scoring for sleep outcome measures in chronic obstructive pulmonary disease. Sleep Med. 2017;37:124-9. doi:10.1016/j.sleep.2017.06.012.

33. Faerman A, Kaplan KA, Zeitzer JM. Subjective sleep quality is poorly associated with actigraphy and heart rate measures in community-dwelling older men. Sleep Med. 2020. doi:10.1016/j.sleep.2020.04.012.

34. McCall C, McCall WV. Objective vs. subjective measurements of sleep in depressed insomniacs: first night effect or reverse first night effect? J Clin Sleep Med. 2012;8:59-65. doi:10.5664/jcsm.1664.

35. Altevogt BM, Colten HR, editors. Sleep disorders and sleep deprivation: An unmet public health problem. Washington, D.C, s.I.: Institute of Medicine; 2006.

36. Bonnet MH, Arand DL. We are chronically sleep deprived. Sleep. 1995;18:908-11.

37. Orzeł-Gryglewska J. Consequences of sleep deprivation. Int J Occup Med Environ Health. 2010;23:95-114.

38. Bianchi MT, editor. Sleep Deprivation and Disease: Effects on the Body, Brain and Behavior. New York: Springer New York; 2014.

39. Borbély AA, Rusterholz T, Achermann P. Three decades of continuous wrist-activity recording: Analysis of sleep duration. J Sleep Res. 2017;26:188-94. doi:10.1111/jsr.12492.

40. Wong PM, Hasler BP, Kamarck TW, Muldoon MF, Manuck SB. Social Jetlag, Chronotype, and Cardiometabolic Risk. The Journal of Clinical Endocrinology Metabolism. 2015;100:4612-20. doi:10.1210/jc.2015-2923.

41. Grandner MA, Patel NP, Gehrman PR, Perlis ML, Pack Al. Problems associated with short sleep: bridging the gap between laboratory and epidemiological studies. Sleep Med Rev. 2010;14:239-47. doi:10.1016/j.smrv.2009.08.001.

42. Chattu VK, Sakhamuri SM, Kumar R, Spence DW, Bahammam AS, Pandi-Perumal SR. Insufficient Sleep Syndrome: Is it time to classify it as a major noncommunicable disease? Sleep Sci. 2018;11:56-64. doi:10.5935/1984-0063.20180013.

43. van den Berg JF, Knvistingh Neven A, Tulen JHM, Hofman A, Witteman JCM, Miedema HME, Tiemeier H. Actigraphic sleep duration and fragmentation are related to obesity in the elderly: the Rotterdam Study. Int J Obes. 2008;32:1083-90. doi:10.1038/ijo.2008.57.

44. Roenneberg T, Merrow M. The Circadian Clock and Human Health. Curr Biol. 2016;26:R432-43. doi:10.1016/j.cub.2016.04.011.

45. Potter GDM, Skene DJ, Arendt J, Cade JE, Grant PJ, Hardie LJ. Circadian Rhythm and Sleep Disruption: Causes, Metabolic Consequences, and Countermeasures. Endocr Rev. 2016;37:584-608. doi:10.1210/er.2016-1083.

46. Veauthier C, Hasselmann H, Gold SM, Paul F. The Berlin Treatment Algorithm: recommendations for tailored innovative therapeutic strategies for multiple sclerosis-related fatigue. The EPMA Journal. 2016;7:1-16. doi:10.1186/s13167-016-0073-3.

47. Bailes S, Baltzan M, Rizzo D, Fichten CS, Grad R, Wolkove N, et al. Sleep disorder symptoms are common and unspoken in Canadian general practice. Fam Pract. 2009;26:294-300. doi:10.1093/fampra/cmp031.

48. Talbot LS, Maguen S, Metzler TJ, Schmitz M, McCaslin SE, Richards A, et al. Cognitive behavioral therapy for insomnia in posttraumatic stress disorder: a randomized controlled trial. Sleep. 2014;37:327-41. doi:10.5665/sleep.3408.

49. Conrad N, Karlik J, Lewandowski Holley A, Wilson AC, Koh J. A Narrative Review: Actigraphy as an Objective Assessment of Perioperative Sleep and Activity in Pediatric Patients. Children (Basel). 2017. doi:10.3390/children4040026.

50. Drake C, Roehrs T, Breslau N, Johnson E, Jefferson C, Scofield H, Roth T. The 10-year risk of verified motor vehicle crashes in relation to physiologic sleepiness. Sleep. 2010;33:745-52. doi:10.1093/sleep/33.6.745.

51. Raj R, Ussavarungsi K, Nugent K. Accelerometer-based devices can be used to monitor sedation/agitation in the intensive care unit. J Crit Care. 2014;29:748-52. doi:10.1016/j.jcrc.2014.05.014.

52. Lafleur KJ. Will adequate sedation assessment include the use of actigraphy in the future? Am J Crit Care. 2005;14:61-3.

53. World Health Organization. WHO / Global recommendations on physical activity for health. https://www.who.int/dietphysicalactivity/factsheet_recommendations/en/. Accessed 17 Jan 2020.

Page $9 / 14$ 
54. Luzak A, Heier M, Thorand B, Laxy M, Nowak D, Peters A, Schulz H. Physical activity levels, duration pattern and adherence to WHO recommendations in German adults. PLoS ONE. 2017;12:e0172503. doi:10.1371/journal.pone.0172503.

55. Aparicio-Ugarriza R, Mielgo-Ayuso J, Benito PJ, Pedrero-Chamizo R, Ara I, González-Gross M. Physical activity assessment in the general population; instrumental methods and new technologies. Nutr Hosp. 2015;31(Suppl 3):219-26. doi:10.3305/nh.2015.31.sup3.8769.

56. Golubnitschaja O, Costigliola V, General EPMA. Report \& Recommendations in Predictive, Preventive and Personalised Medicine 2012: White Paper of the European Association for Predictive, Preventive and Personalised Medicine. EPMA J. 2012;3:14. doi:10.1186/1878-5085-3-14.

57. Steur LMH, Kaspers GJL, van Someren EJW, van Eijkelenburg NKA, van der Sluis IM, Dors N, et al. Sleep-wake rhythm disruption is associated with cancerrelated fatigue in pediatric acute lymphoblastic leukemia. Sleep. 2019. doi:10.1093/sleep/zsz320.

58. Naismith SL, Rogers NL, Hickie IB, Mackenzie J, Norrie LM, Lewis SJG. Sleep well, think well: sleep-wake disturbance in mild cognitive impairment. J Geriatr Psychiatry Neurol. 2010;23:123-30. doi:10.1177/0891988710363710.

59. Beaulieu-Bonneau S, Hudon C. Sleep disturbances in older adults with mild cognitive impairment. Int Psychogeriatr. 2009;21:654-66. doi:10.1017/S1041610209009120.

60. Cochrane A, Robertson IH, Coogan AN. Association between circadian rhythms, sleep and cognitive impairment in healthy older adults: an actigraphic study. J Neural Transm. 2012;119:1233-9. doi:10.1007/s00702-012-0802-2.

61. Paul MA, Love RJ, Jetly R, Richardson JD, Lanius RA, Miller JC, et al. Blunted Nocturnal Salivary Melatonin Secretion Profiles in Military-Related Posttraumatic Stress Disorder. Front Psychiatry. 2019;10:882. doi:10.3389/fpsyt.2019.00882.

62. Rezaei N, Grandner MA. Changes in sleep duration, timing, and variability during the COVID-19 pandemic: Large-scale Fitbit data from 6 major US cities. Sleep Health. 2021. doi:10.1016/j.sleh.2021.02.008.

63. Garmin. Bewegungsverhalten in Zeiten der Pandemie. 2020. http://m.mails.garmin.com/nl/jsp/m.jsp? C=\%40tJcwd1J8HP9Qla6beoE3RCc\%2FvHMuKwuWyN2IfaMw19o\%3D\&utm_source=EMEA\&utm_medium=email\&utm_campaign=deCH\%20Delivery\%2C\%20EMEA\%2C\%20COVID-19\%20GC\%20Trends\%20March\%2C\%2013590. Accessed 12 May 2020.

64. Prather AA, Janicki-Deverts D, Hall MH, Cohen S. Behaviorally Assessed Sleep and Susceptibility to the Common Cold. Sleep. 2015. doi: $10.5665 /$ sleep.4968.

65. Werner H, Molinari L, Guyer C, Jenni OG. Agreement rates between actigraphy, diary, and questionnaire for children's sleep patterns. Arch Pediatr Adolesc Med. 2008;162:350-8. doi:10.1001/archpedi.162.4.350.

66. Golubnitschaja O, Flammer J. Individualised patient profile: clinical utility of Flammer syndrome phenotype and general lessons for predictive, preventive and personalised medicine. The EPMA Journal. 2018;9:15-20. doi:10.1007/s13167-018-0127-9.

67. Koolhaas CM. Sedentary time assessed by actigraphy and mortality. Activity and Health. 2018:153.

68. Forberger S, Reisch L, Kampfmann T, Zeeb H. Nudging to move: a scoping review of the use of choice architecture interventions to promote physical activity in the general population. Int J Behav Nutr Phys Act. 2019;16:77. doi:10.1186/s12966-019-0844-z.

69. Lakerveld J, Mackenbach JD, Boer F de, Brandhorst B, Broerse JEW, Bruijn G-J de, et al. Improving cardiometabolic health through nudging dietary behaviours and physical activity in low SES adults: design of the Supreme Nudge project. BMC Public Health. 2018;18:899. doi:10.1186/s12889-0185839-1.

70. Winnebeck EC, Fischer D, Leise T, Roenneberg T. Dynamics and Ultradian Structure of Human Sleep in Real Life. Curr Biol. 2018;28:49-59.e5. doi:10.1016/j.cub.2017.11.063.

71. Figueiro MG. Delayed sleep phase disorder: clinical perspective with a focus on light therapy. Nature Science of Sleep. 2016;8:91-106. doi:10.2147/NSS.S85849.

72. Birchler-Pedross A, Schroder CM, Munch M, Knoblauch V, Blatter K, Schnitzler-Sack C, et al. Subjective well-being is modulated by circadian phase, sleep pressure, age, and gender. J Biol Rhythms. 2009;24:232-42. doi:10.1177/0748730409335546.

73. Baglioni C, Battagliese G, Feige B, Spiegelhalder K, Nissen C, Voderholzer U, et al. Insomnia as a predictor of depression: a meta-analytic evaluation of longitudinal epidemiological studies. J Affect Disord. 2011;135:10-9. doi:10.1016/j.jad.2011.01.011.

74. Hertenstein E, Feige B, Gmeiner T, Kienzler C, Spiegelhalder K, Johann A, et al. Insomnia as a predictor of mental disorders: A systematic review and metaanalysis. Sleep Med Rev. 2019;43:96-105. doi:10.1016/j.smrv.2018.10.006.

75. Baglioni C, Riemann D. Is chronic insomnia a precursor to major depression? Epidemiological and biological findings. Curr Psychiatry Rep. 2012;14:5118. doi:10.1007/s11920-012-0308-5.

76. Walther S, Stegmayer K, Horn H, Razavi N, Müller TJ, Strik W. Physical Activity in Schizophrenia is Higher in the First Episode than in Subsequent Ones. Front Psychiatry. 2014;5:191. doi:10.3389/fpsyt.2014.00191.

77. Wee ZY, Yong SWL, Chew QH, Guan C, Lee TS, Sim K. Actigraphy studies and clinical and biobehavioural correlates in schizophrenia: a systematic review. J Neural Transm. 2019;126:531-58. doi:10.1007/s00702-019-01993-2.

78. Tsanas A, Woodward E, Ehlers A. Objective Characterization of Activity, Sleep, and Circadian Rhythm Patterns Using a Wrist-Worn Actigraphy Sensor: Insights Into Posttraumatic Stress Disorder. JMIR Mhealth Uhealth. 2020;8:e14306. doi:10.2196/14306.

79. Patterson F, Malone SK, Lozano A, Grandner MA, Hanlon AL. Smoking. Screen-Based Sedentary Behavior, and Diet Associated with Habitual Sleep Duration and Chronotype: Data from the UK Biobank. Ann Behav Med. 2016;50:715-26. doi:10.1007/s12160-016-9797-5.

80. Jike M, Itani O, Watanabe N, Buysse DJ, Kaneita Y. Long sleep duration and health outcomes: A systematic review, meta-analysis and meta-regression. Sleep Med Rev. 2018;39:25-36. doi:10.1016/j.smrv.2017.06.011.

81. Medalie JH, Zyzanski SJ, Langa DM, Stange KC. The family in family practice: is it a reality? J Fam Pract. 1998;46:390-6.

Page $10 / 14$ 
82. Cox A, Ness K, Carlson R. International Perspectives on Depression in the Workplace.

83. Spitzer M. Mediennutzung in Zeiten von Corona. Nervenheilkunde. 2020;39:698-703. doi:10.1055/a-1193-8248.

84. Peracchia S, Curcio G. Exposure to video games: effects on sleep and on post-sleep cognitive abilities. A sistematic review of experimental evidences. Sleep Sci. 2018;11:302-14. doi:10.5935/1984-0063.20180046.

85. Rod NH, Dissing AS, Clark A, Gerds TA, Lund R. Overnight smartphone use: A new public health challenge? A novel study design based on high-resolution smartphone data. PLoS ONE. 2018;13:e0204811. doi:10.1371/journal.pone.0204811.

86. Kurganova YM, Danilov AB. Melatonin in Chronic Pain Syndromes. Neurosci Behav Physi. 2017;47:806-12. doi:10.1007/s11055-017-0472-5.

87. Kreuter J. Influence of chronobiology on the nanoparticle-mediated drug uptake into the brain. Pharmaceutics. 2015;7:3-9. doi:10.3390/pharmaceutics7010003.

88. Dagan Y, Ayalon L. Case study: psychiatric misdiagnosis of non-24-hours sleep-wake schedule disorder resolved by melatonin. J Am Acad Child Adolesc Psychiatry. 2005;44:1271-5. doi:10.1097/01.chi.0000181040.83465.48.

89. Dagan Y. Circadian rhythm sleep disorders (CRSD). Sleep Med Rev. 2002;6:45-55. doi:10.1053/smrv.2001.0190.

90. Borbély AA, Daan S, Wirz-Justice A, Deboer T. The two-process model of sleep regulation: a reappraisal. J Sleep Res. 2016;25:131-43. doi:10.1111/jsr.12371.

91. Blume C, Garbazza C, Spitschan M. Effects of light on human circadian rhythms, sleep and mood. Somnologie. 2019.

92. Rosenbaum S, Hobson-Powell A, Davison K, Stanton R, Craft LL, Duncan M, et al. The Role of Sport, Exercise, and Physical Activity in Closing the Life Expectancy Gap for People with Mental IIIness: An International Consensus Statement by Exercise and Sports Science Australia, American College of Sports Medicine, British Association of Sport and Exercise Science, and Sport and Exercise Science New Zealand. Translational Journal of the American College of Sports Medicine. 2018;3:72-3. doi:10.1249/TJX.0000000000000061.

\section{Figures}

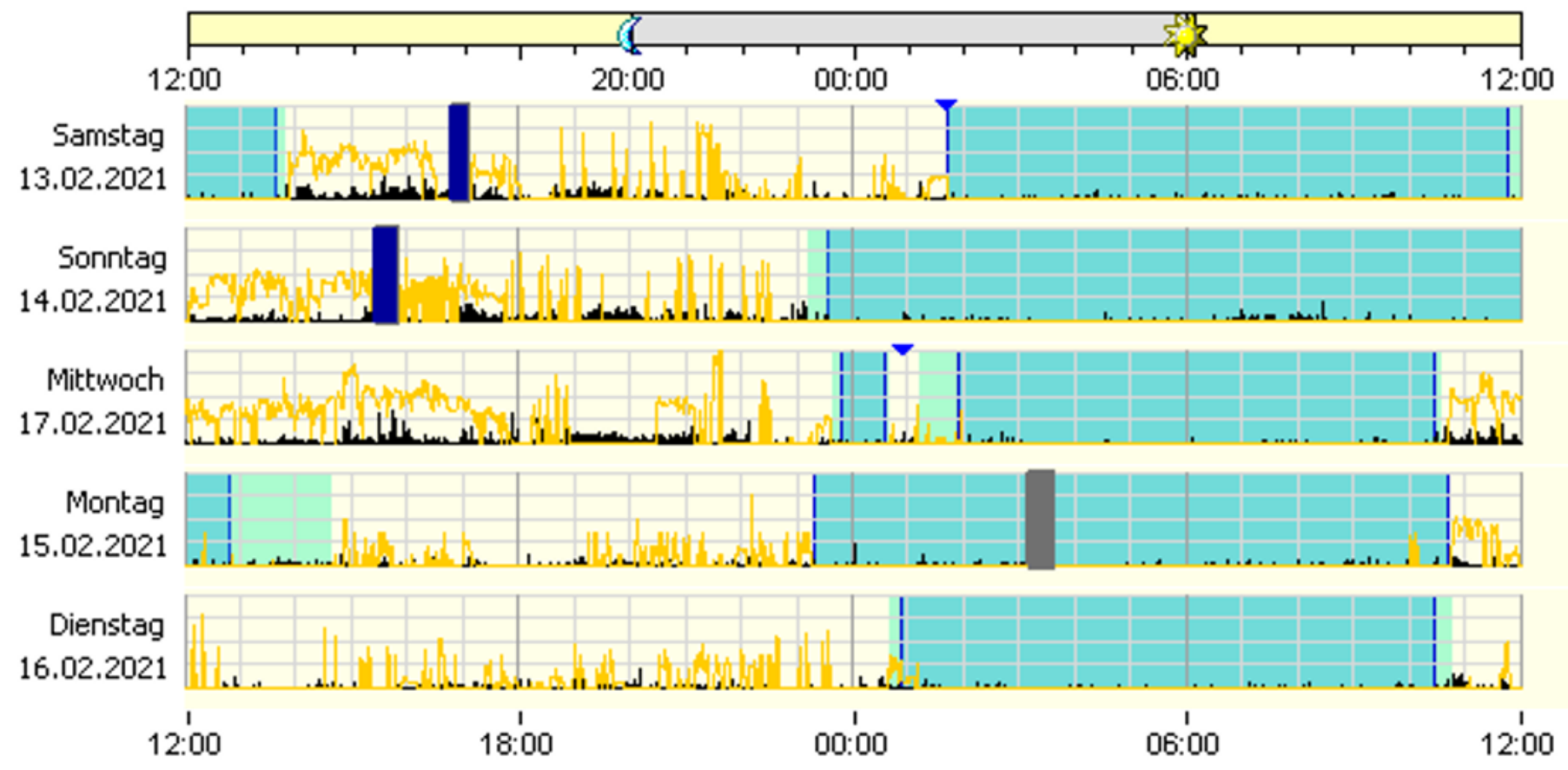

Figure 1

Section of a 2-week actigraphy with significantly prolonged bed-lying phase, decreased daytime activity, several days without significant daytime light exposure. The dark areas indicate the patient's bed phase, black indicates motor activity, yellow light exposure. 


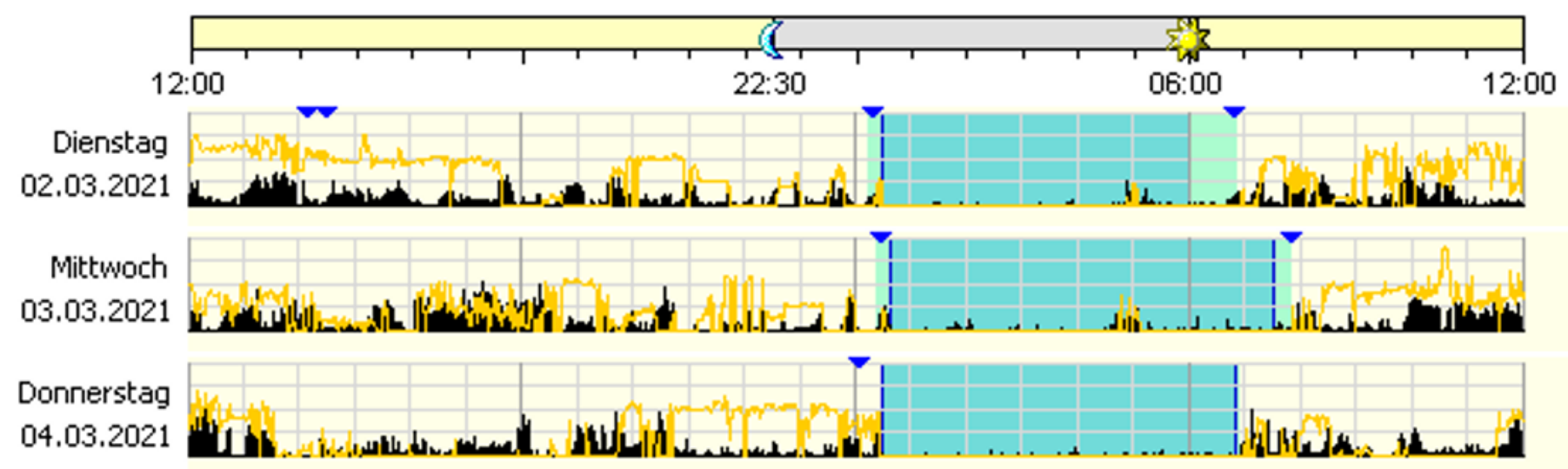

a

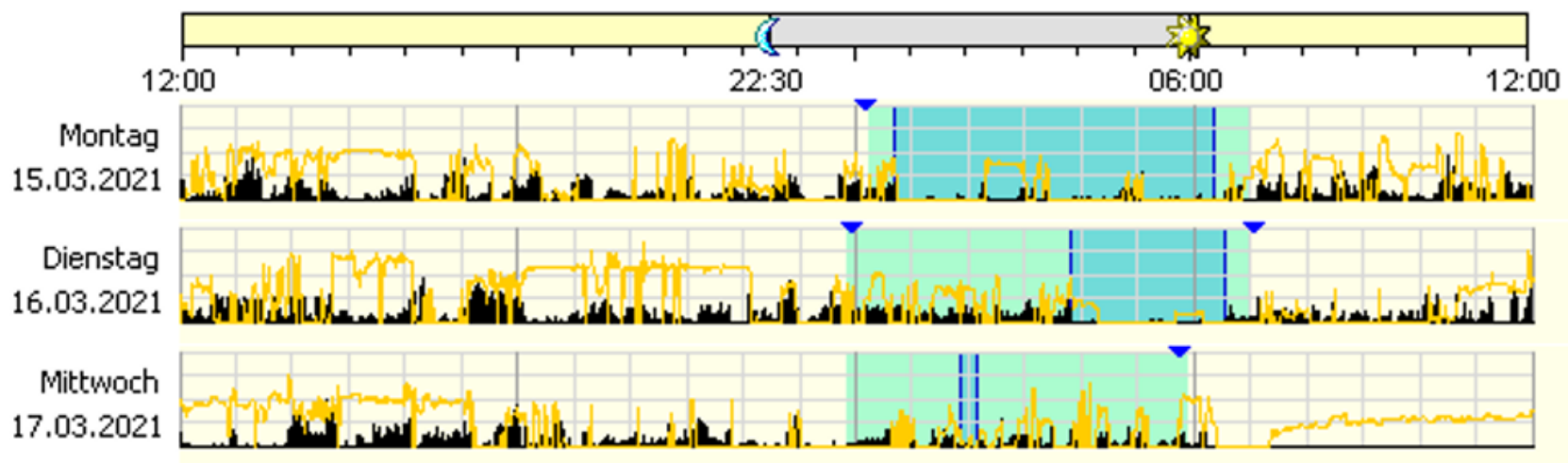

b

Figure 2

a): Recorded phase with normal sleeping behaviour, in the presence of the partner. The dark areas indicate the patient's bed phase, black indicates motor activity, yellow light exposure. b): Decompensated gambling addiction in the further course in the absence of the family members. The dark areas indicate the patient's bed phase, black indicates motor activity, yellow light exposure. 


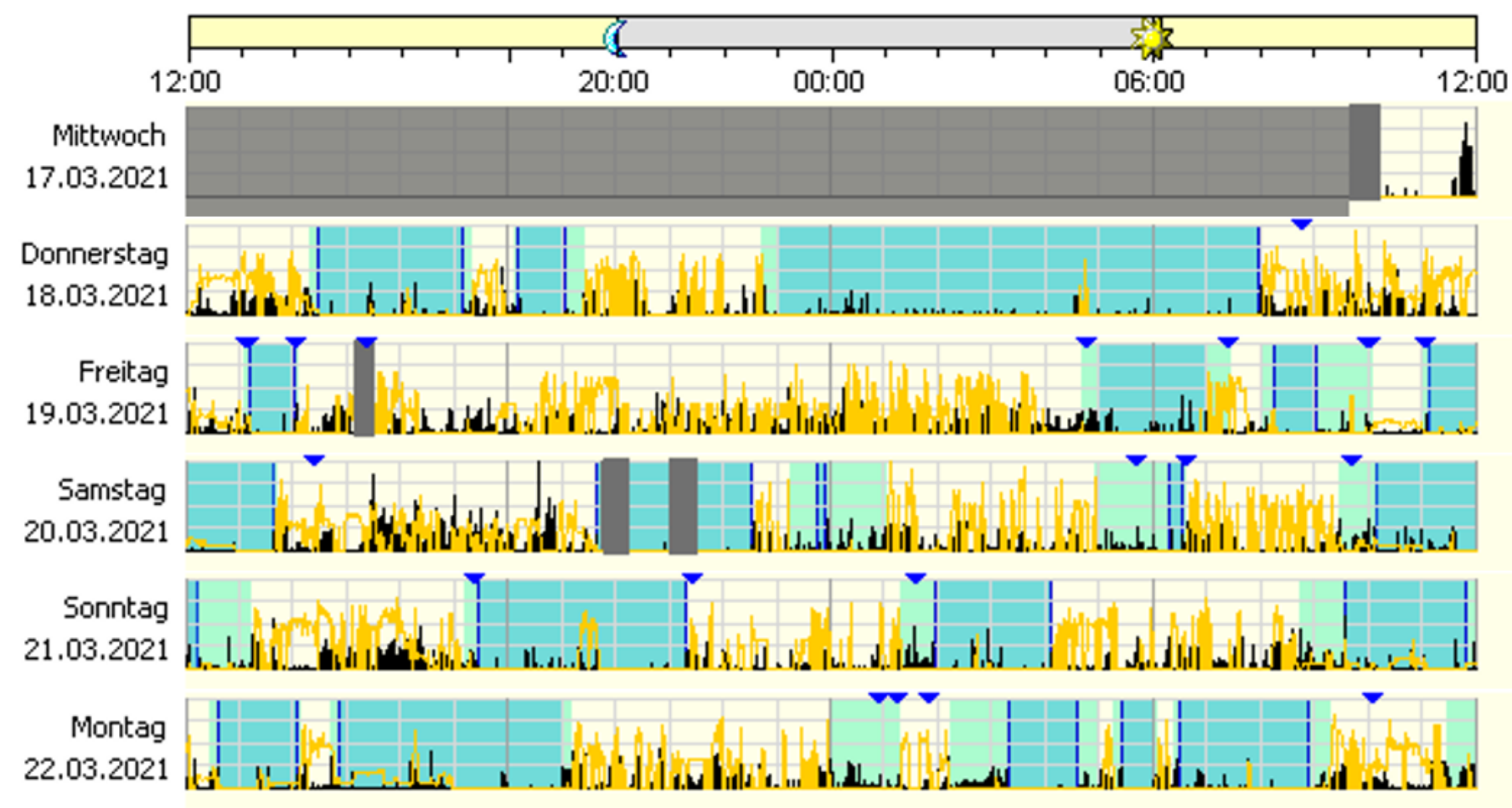

\section{Figure 3}

The section of a 3-week actigraphy shows an unidentifiable main resting phase, various sleep attempts occur (indicated by the triangles marking the beginning and end of a sleep attempt, markings are often forgotten). The disorganised supply of pain medication and sedative medication was problematic. From the actigraphy, it becomes clear that GP therapy recommendations on intake times probably cannot be implemented. 


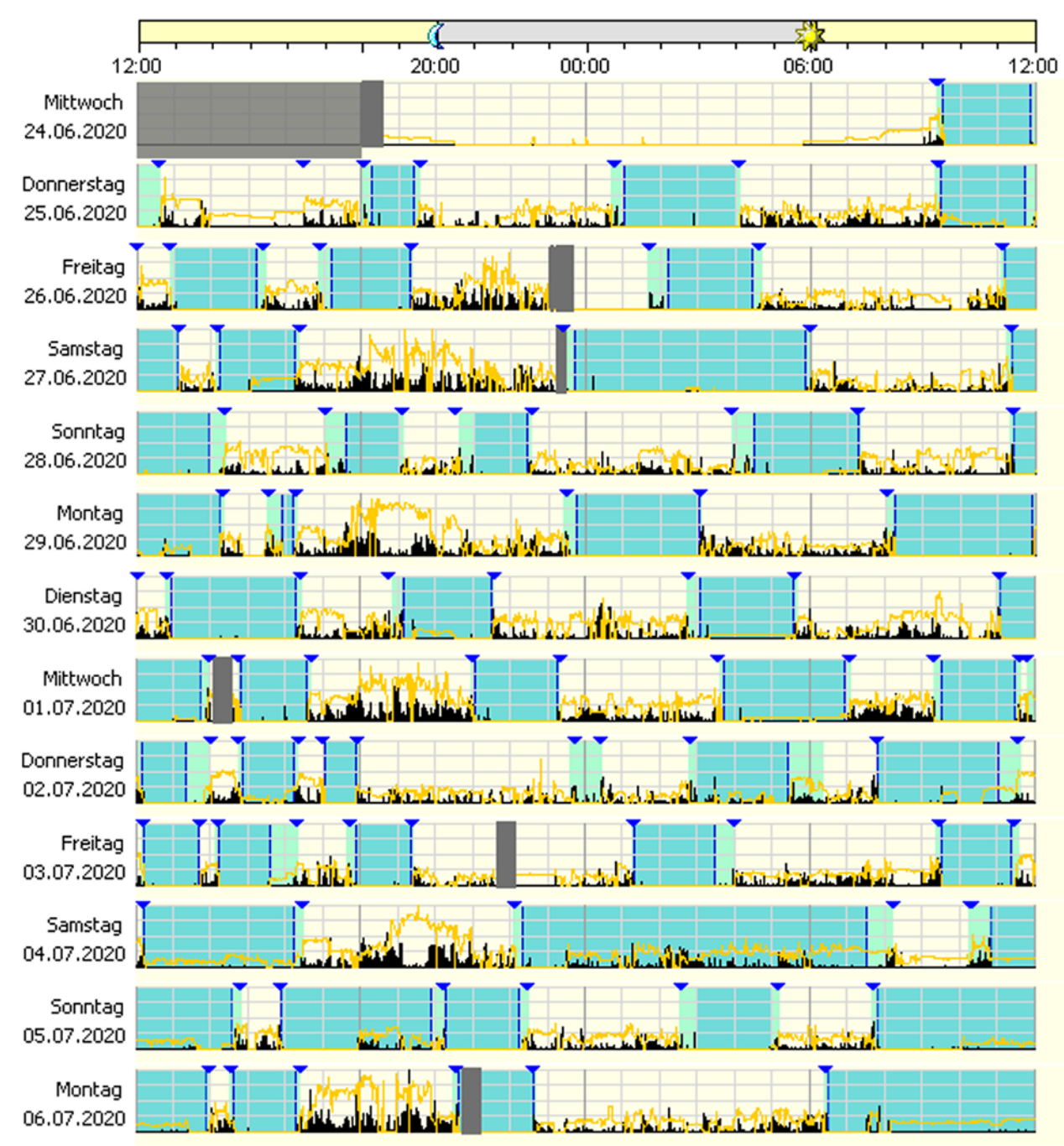

\section{Figure 4}

Example of a wrist actigraphy of a psychiatric out-patient. Treated in a general practitioner setting due to subjective sleep disturbance against a background of depression, addiction with a history of increased alcohol consumption. Hypnotics and drive-enhancing antidepressants were used, and the patient was alcohol-abstinent during the recording period. The actigraphy shows a completely abolished structure of the day-night rhythm, blue triangles corresponding to subjective patient markers corresponding to the limits of bedtime. The continuously recorded activity in the 24-hour period appears in black, the light irradiation in yellow. Sleep expert diagnosis: circadian sleep-wake-rhythm disorder, an indication for inpatient rhythmic therapy was given. 